\title{
Pathogenicity, Fungicide Resistance, and Genetic Variability of Phytophthora rubi Isolates from Raspberry (Rubus idaeus) in the Western United States
}

Jane E. Stewart and Duncan Kroese, USDA-ARS-Horticultural Crops Research Laboratory, Corvallis, OR 97330; Javier F. Tabima, Department of Botany and Plant Pathology, Oregon State University, Corvallis, OR 97330; Meredith M. Larsen, USDA-ARSHorticultural Crops Research Laboratory, Corvallis, OR 97330; Valerie J. Fieland, Department of Botany and Plant Pathology, Oregon State University, Corvallis, OR 97330; Caroline M. Press, Inga A. Zasada, and Niklaus J. Grünwald, USDA-ARS-Horticultural Crops Research Laboratory, Corvallis, OR 97330

\begin{abstract}
Stewart, J. E., Kroese, D., Tabima, J. F., Larsen, M. M., Fieland, V. J., Press, C. M., Zasada, I. A., and Grünwald, N. J. 2014. Pathogenicity, fungicide resistance, and genetic variability of Phytophthora rubi isolates from raspberry (Rubus idaeus) in the Western United States. Plant Dis. 98:1702-1708.

Root rot of raspberry (Rubus idaeus), thought to be primarily caused by Phytophthora rubi, is an economically important disease in the western United States. The objectives of this study were to determine which Phytophthora species are involved in root rot, examine the efficacy of different isolation methods (cane, root, and root/soil baiting with young raspberry plants), and determine if pathogenicity, fungicide resistance, and/or genetic variation exists among $P$. rubi isolates collected from raspberry fields in Washington, Oregon, and California. Of 275 samples, direct isolation from cane material resulted in a greater number of $P$. rubi isolates (39\%), whereas root/soil baiting yielded the

210 of the total 597 collected Phytophthora isolates showed that all but one isolate (identified as P. bisheria) were P. rubi. Results of the pathogenicity and fungicide resistance to mefenoxam comparing 14 total isolates from Washington, Oregon, and California showed that isolates were similarly virulent against red raspberry and the $\mathrm{EC}_{50}$ frequency distributions showed no significant difference. These results, combined with amplified fragment length polymorphism results show that $P$. rubi isolates from Washington, Oregon, and California represent one large mixed population. This work provides novel insights into the isolation and biology of $P$. rubi in western U.S. raspberry production systems.
\end{abstract} least $(11 \%)$. Sequencing of the internal transcribed spacer region of
U.S. raspberry (Rubus idaeus) production occurs mostly in the western states, with over $90 \%$ of total fresh market production coming from California, and over $90 \%$ of total processing production grown in Washington (33). Within these states, raspberry production is heavily concentrated in regions with optimal climate and soils for raspberry production, which includes a wet, warm spring and a fall season with mild winters. Most of California's production is located in Santa Cruz and Ventura counties; approximately 90\% of Washington's production is in Whatcom and Skagit counties; and the Willamette Valley is Oregon's primary growing region. Prime land for this crop is limited, and growers must often replant raspberry crops without crop rotation in fields previously planted to raspberry. In Washington, 95\% of replanted fields and $50 \%$ of new fields are fumigated prior to raspberry establishment, primarily to control raspberry root rot and root lesion nematode (Pratylenchus penetrans) (22). In California, 20\% of new fields are fumigated prior to raspberry establishment (3).

Root rot caused by Phytophthora spp. has been a common and major disease complex of red raspberry since the early 1950s in western North America $(4,36)$. The aboveground symptoms include scorched or bronzed leaves that eventually flag, and stunted growth of the fruit stems. Berries of infected plants will remain small and wither before ripening. Phytophthora-infected roots become necrotic, and plants may form some new roots and appear to recover, but the new roots are typically weak and lack lateral

Corresponding author: Niklaus J. Grünwald,

E-mail: Nik.Grunwald@ARS.USDA.GOV

Accepted for publication 4 June 2014.

http://dx.doi.org/10.1094/PDIS-11-13-1130-RE

This article is in the public domain and not copyrightable. It may be freely reprinted with customary crediting of the source. The American Phytopathological Society, 2014. development, and new feeder roots are killed. The new roots subsequently become infected during cold, wet weather so that the plant progressively declines and becomes unproductive. Reddish lesions often extend above and below the point of infection on the roots and crowns, and eventually these lesions girdle the whole plant. The disease is a major factor limiting the economic production of raspberries in the Pacific Northwest. Due to short rotations and frequent fumigation, Phytophthora root rot is typically well controlled, but with changes to fumigation regulations a re-emergence of Phytophthora root rot in California could occur (34).

Although 10 different species of Phytophthora have been reported as raspberry root pathogens $(36,37,39)$, it has long been assumed that a single Phytophthora species, P. rubi, is responsible for the vast majority of root rot symptoms in the Pacific Northwest, and industry management practices have been driven by this assumption. However, a recent field study from Whatcom County in Washington State showed that other species of Phytophthora could potentially be involved in disease development (19). This study detected Phytophthora in both planting stock and established red raspberry fields over 4 years. Utilizing a polymerase chain reaction (PCR)-based test, roughly half of the Phytophthora-infected plants sampled were positive for $P$. rubi while the other half were not, presumably because they were infected by other Phytophthora spp. (19). It is possible that several Phytophthora spp. comprising a species complex is responsible for Phytophthora root rot of raspberry in the Pacific Northwest and California.

An integrative management approach, including development of resistant raspberry cultivars, fungicides and fumigants, and avoidance of wet soils, is suggested for control of this disease $(12,20,38)$. A clear understanding of the species involved is essential for the management of Phytophthora root rot. For example, host resistance may be specific to each Phytophthora sp. Some red and black raspberry cultivars resistant to $P$. fragariae are susceptible to $P$. megasperma (37). The newly released processing variety 'Cascade Bounty' is resistant to P. rubi; the widely planted fresh market variety 'Tulameen' is susceptible; and the predominant 
processing cultivar 'Meeker' has an intermediate reaction (13). However, the reaction of these varieties to other Phytophthora spp. is unknown. Furthermore, it is important to understand how much genetic and pathogenic variation exists in $P$. rubi and other Phytophthora spp. on raspberry. Once species abundance and distribution as well as genetic and phenotypic diversity are better understood, disease management can be tailored to the Phytophthora pathogen in question.

Our overarching goal is to improve soilborne disease management in raspberry production systems. While conducting preliminary work, we observed that $P$. rubi is exceedingly difficult to isolate from red raspberry roots. Therefore, our first objective was to examine the isolation efficacy of Phytophthora from red raspberry using different isolation methods (cane, roots, and root/soil baiting with young red raspberry plants). Given the uncertainly of which Phytophthora species cause root rot on red raspberry, we also investigated which Phytophthora species are involved in raspberry root rot and red stele. A final objective was to determine if there was variation in virulence, fungicide resistance, and/or genetic variation among isolates collected from raspberry fields in the western United States.

\section{Materials and Methods}

Sample collection. Raspberry plants showing symptoms of raspberry root rot were preferentially sampled. During late fall and early spring of 2011-2012, samples were collected from 3, 3, and 2 fields in Oregon, Washington, and California, respectively (Fig. 1). In Oregon and Washington, sampling consisted of removing 1 to 2 canes and associated roots and soil from diseased plants. In California, where the plants were much younger, whole raspberry plants, including roots and soil, were removed. Samples were placed in coolers, on ice, and stored at $4{ }^{\circ} \mathrm{C}$ until processed. All samples were processed within 2 to 3 days of collection.

Isolation of Phytophthora from raspberry. To maximize our ability to isolate and detect Phytophthora in raspberry, each sample was processed in three different ways: (i) direct isolation from canes, (ii) direct isolation from roots, and (iii) baiting from root and soil materials with young 'Meeker' raspberry tissue culture plants. For each sample, soil was separated from plant material and placed in a plastic bag and stored at $4^{\circ} \mathrm{C}$ until used for baiting. Canes and roots were rinsed with tap water to remove excess soil and other debris. Each plant sample was then divided into three parts: canes (for cane isolation), coarse roots (ranging from approximately 1 to $4 \mathrm{~cm}$ for root isolation), and fine roots ( $<1 \mathrm{~mm}$ for baiting).

Cane isolation. Symptomatic areas on each raspberry cane were targeted for isolation. The outer cambium layer on the cane was scraped using a sterilized blade to reveal the active front of lesions. Six to eight small pieces $(2 \times 5 \mathrm{~mm})$ were cut from the interface of healthy and diseased tissue from each cane. Pieces were placed in $10 \%$ ( $\mathrm{vol} / \mathrm{vol}$ ) sodium hypochlorite for 1 to $3 \mathrm{~min}$ and blotted with $70 \%$ ethanol. Pieces were then submerged into $13-\mathrm{mm}$ petri plates containing CMA (Difco cornmeal agar, $8.5 \mathrm{~g} / 500 \mathrm{ml}$ of deionized water) amended with pimaricin $(0.2 \mathrm{ml})$, ampicillin- $\mathrm{Na}(0.125 \mathrm{~g})$, rifampicin $(0.005 \mathrm{~g})$, and pentachloronitrobenzene (PCNB $2.5 \mathrm{ml}$ ) (CMA-PARP) (15). CMA-PARP plates were then incubated at $18^{\circ} \mathrm{C}$ in the dark for up to 10 days. Plates were examined every 2 days for Phytophthora mycelial growth. When growth occurred, hyphal tips were transferred to a new CMA-PARP plate. Only one transfer occurred per cane piece in a plate.

Root isolation. Coarse root samples were placed in plastic Nalgene (Thermo Scientific, Waltham, MA) containers and the opening covered with cheesecloth. Samples were then rinsed in tap water continuously for $1 \mathrm{~h}$, washed for $2 \mathrm{~min}$ in $50 \%$ Ivory dish soap (Procter \& Gamble, Cincinnati, OH), followed by 6 to 7 distilled water rinses. Symptomatic roots were cut into small pieces, blotted on ethanol-soaked paper towels, and submerged into CMAPARP media. CMA-PARP plates were incubated at $18^{\circ} \mathrm{C}$ in the dark for up to 10 days. Plates were examined every 2 days for Phytophthora mycelial growth. When growth occurred, hyphal tips were transferred to a new CMA-PARP plate. Only one transfer occurred per root piece in a plate.

Baiting. Cone-tainers (254 mm; D4OH Deepots; Stuewe and Sons, Inc., Tangent, OR) were filled halfway with Sunshine Brand Professional Growing Mix (Bellevue, WA). Fine root material and/or soil remaining after isolations (see above) thought to be infected with $P$. rubi, was placed into the Cone-tainer. Raspberry 'Meeker' tissue culture plants ( 3 to 4 weeks old; Sakuma Bros., Burlington, WA) were then placed directly on top of potentially infected root and soil material. The remaining area in the Conetainer was filled with growing mix to $2.5 \mathrm{~cm}$ from the top of the pot. Cone-tainers were watered thoroughly and placed in a Conviron growth chamber (Winnipeg, Canada) set at $18^{\circ} \mathrm{C}$ with a $12 \mathrm{~h}$ light/dark cycle. While in the growth chamber, plants were watered by flooding. To achieve flooding, Cone-tainers were placed into 532-ml plastic cups (Solo; Dart Container Corporation, Tumwater, WA) filled with tap water. Plants remained in the cups for 2 days, after which cups were removed. After 1 day without water, cups were refilled and the flooding cycle started again. This schedule of irrigation was followed for the entire time the plants

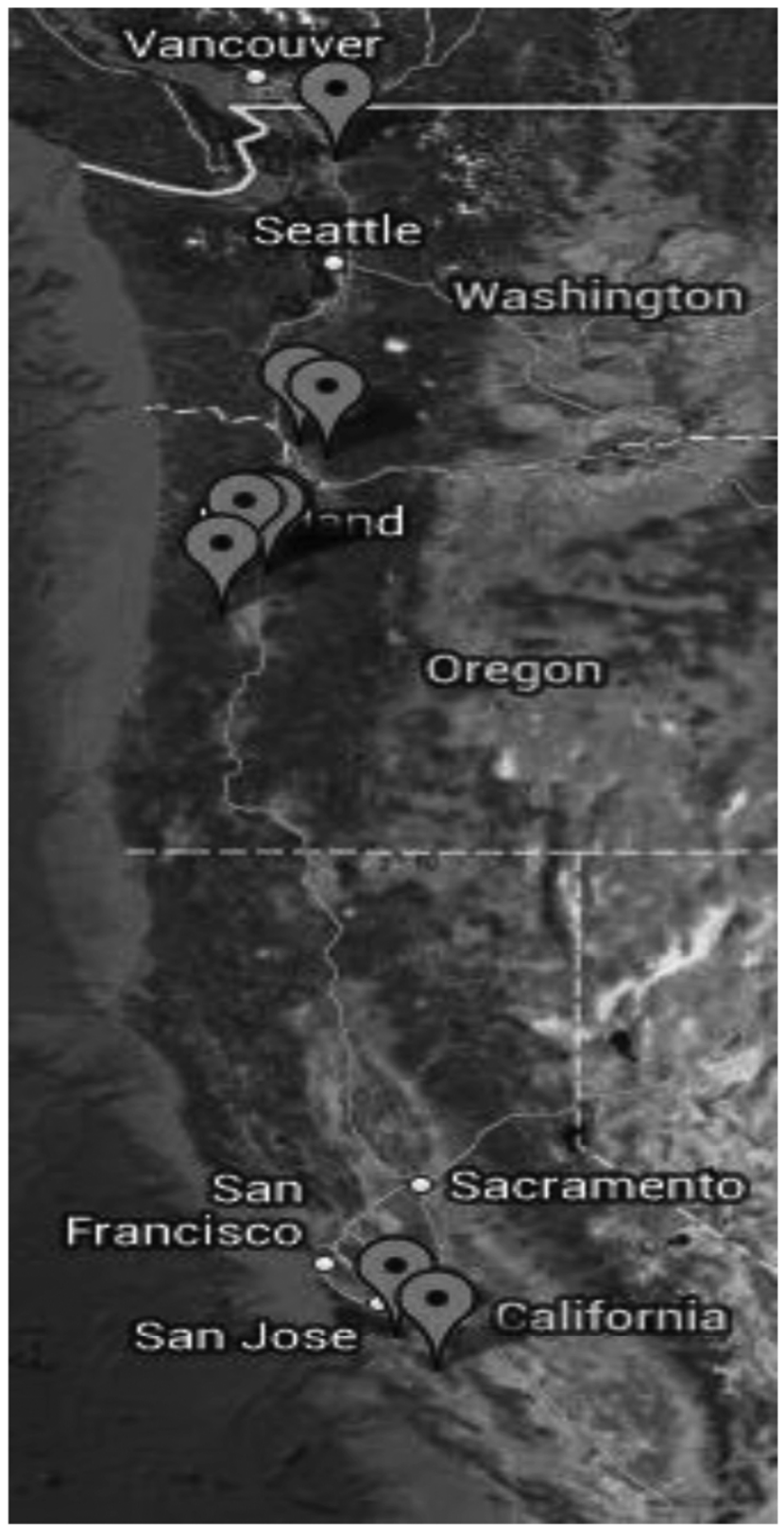

Fig. 1. Approximate geographic locations of raspberry (Rubus idaeus) fields sampled for Phytophthora rubi in the western United States. 
were in the growth chamber. Plants were overhead watered when needed. Visual inspections of the plants occurred every day, and when plants became symptomatic, after 2 to 4 weeks, they were harvested. Plants were removed from the Cone-tainer, roots were washed, and the plant was processed using the cane isolation method described above. Plants that never showed symptoms of infection were allowed to stay in the growth chamber for no longer than 5 weeks, at which point all plants were harvested and processed using the cane isolation method described above.

Statistical analysis of isolation techniques. Recovery rate of each method was compared using a Fisher exact test on binomial data of presence and absence on each plant. Statistical analyses were completed in JMP Pro 10 (SAS International Incorporated, Cary, NC).

Identification of Phytophthora species. After isolates were transferred to new CMA-PARP plates, potential Phytophthora spp. colonies were re-plated onto V8-PAR media (100 ml V8 vegetable juice, $800 \mathrm{ml}$ water, $2 \mathrm{~g} \mathrm{CaCO}_{3} 1 \mathrm{~b}$-sitosterol [EMD Chemicals, Inc., Darmstadt, Germany]; $15 \mathrm{~g}$ agar; $900 \mathrm{ml}$ deionized water amended with ampicillin-Na $[0.125 \mathrm{~g}]$, rifampicin $[0.005 \mathrm{~g}]$, and pentachloronitrobenzene [PCNB $2.5 \mathrm{ml}$ ]). Using a quick DNA extraction method, a subsample of isolates from each field were identified to species by sequencing the internal transcribed spacer (ITS) of the rDNA as described previously (10). PCR products were sequenced using ABI PRISM BigDye Terminator 3.1 chemistry (Applied Biosystems [ABI], Foster City, CA) and analyzed on an Applied Biosystems 3730 capillary sequencer at the Oregon State University Center for Genome Research and Biocomputing Core Laboratory (Corvallis, OR).

Pathogenicity trials. A total of $13 P$. rubi isolates were selected for virulence assays on a susceptible raspberry cultivar 'Meeker' including 5, 4, and 4 isolates from California, Oregon, and Washington, respectively. $P$. rubi inoculum was prepared using a vermiculite, V8 broth, and oat mixture. Vermiculite $\left(675 \mathrm{~cm}^{3}\right)$ was mixed with $525 \mathrm{ml} \mathrm{V8}$ broth $(200 \mathrm{ml} \mathrm{V8}$ vegetable juice, $800 \mathrm{ml}$ water, 2 $\mathrm{g} \mathrm{CaCO}_{3}$ ) and $30 \mathrm{~cm}^{3}$ of roughly ground oat seed and added to a 1.8-liter glass jar. The jar was closed with a lid with four $10-\mathrm{cm}$ holes, and a $110 \times 1.59 \mathrm{~mm}$ thick round PTEE synthetic filter (Fungi Perfecti, Olympia, WA) was placed between the lip of the jar and the lid. The jar was then autoclaved and allowed to cool for $24 \mathrm{~h}$. After cooling, the jar was again autoclaved and allowed to cool for another $24 \mathrm{~h}$. In a laminar flow hood, five 6-mm plugs were removed from 14- to 21-day-old V8 agar plates that contained an individual $P$. rubi isolate and added to a jar. The jars for the control treatments were prepared in the same manner as the inoculated treatments without any agar plugs being added. All the jars were then allowed to sit in the dark at room temperature for 4 weeks. During the 4-week incubation time, the jars were shaken once a week to break clumps of hyphae and redistribute the inoculum within the media of the jar.

After the incubation period, the content of each jar was mixed with $10,000 \mathrm{~cm}^{3}$ of Sunshine Brand Professional Growing Mix in an 8-liter, stainless steel, twin-shell blender (Patterson-Kelley, East Stroudsburg, PA) resulting in an approximate inoculum to growing media ratio of 1:10 ( $\mathrm{vol} / \mathrm{vol})$. The controls consisted of growing media only. Inoculated or noninoculated media was then added to D40H Deepots Cone-tainers and a raspberry Meeker tissue culture plant was planted into each Cone-tainer. For each isolate and control, three replications were prepared, with each replication consisting of nine Cone-tainer/plants together in a rack, for a total of 27 plants per isolate or control. Two different noninoculated control treatments were maintained throughout the experiment. One was simply watered and fertigated with 20-20-20 NPK (J.R. Peters, Allentown, PA) in a typical overhead fashion, while the other control was watered and fertigated the same as the rest of the inoculated treatments using a flood irrigation technique (7). This technique involved fertigating up to three times a week by immersing Cone-tainers in 473-ml cups (Conex Classic Clear PET, Dart Container Corporation, Tumwater, WA) filled with 20-20-20 NPK for 6 to $8 \mathrm{~h}$, as well as immersing Cone-tainers in 946-ml (Conex Clas- sic RE-PETE, Dart Container Corporation) cups of water for $48 \mathrm{~h}$ once every 2 weeks. Overhead watering was done on all treatments as needed to keep uniform moisture. The experiment was arranged in a randomized block design in a $16^{\circ} \mathrm{C}$ greenhouse with a 12 -h day/night cycle. To allow for an experimental repeat, the experiment was conducted twice.

Plants were allowed to grow in the greenhouse for 4 weeks. At harvest, each plant was removed from the Cone-tainer and the roots of were washed to remove growth media. For each plant, a number of characteristics were measured or observed. First, the foliage of each plant was rated on a scale of 0 to 4 , with 0 being healthy, 1 being stunted, 2 being stunted and chlorotic, 3 being stunted, chlorotic, and parts of the plant dead/dying, and 4 being dead/dying. Second, the length of the longest root was measured and recorded. Third, the top of the plant was removed and placed into a paper bag, and then in a $70^{\circ} \mathrm{C}$ drying oven. The tops of the plants were dried for 1 week, after which they were removed and the mass of each was measured and recorded. Finally, after the top was removed, each root system was rated on the 0 to 12 HorsfallBarratt scale (14), with 0 being $0 \%$ diseased roots and 12 being $100 \%$ diseased roots. Foliar and root rating were analyzed using contingency tables along with Wilcoxon rank sums tests. Pairwise differences between isolates/treatments were tested using a Fisher exact test. Dry foliage weight and root length were analyzed using a fit least squares model blocked by replication and nested within study. Least squared means differences were compared using Turkey's HSD test $(\alpha=0.01)$ in JMP Pro 10 .

Mefenoxam sensitivity trials. Mycelial inhibition was determined by calculating the mycelial growth of the same $P$. rubi isolates used in the pathogenicity trials on fungicide-amended PDA medium relative to the growth of controls of resistant and susceptible isolates of $P$. infestans. PDA was amended with mefenoxam (Ridomil Gold; Syngenta, Greensboro, NC) at 0, 0.01, 0.1, 1, 10, 100 , and $1,000 \mu \mathrm{g}$ a.i./ml. Three replicates of each fungicide concentration were used for each isolate, and the experiment was conducted twice. For inoculations, mycelial plugs $(5 \mathrm{~mm}$ in diameter) were removed from the periphery of a 6-day-old colony of each $P$. rubi and $P$. infestans isolate using a cork borer and placed upside down onto fungicide-amended PDA. Dishes were incubated at $18^{\circ} \mathrm{C}$ for 6 days in the dark. The average colony diameter was determined by measuring each colony in two perpendicular directions. A linear regression analysis was performed to calculate the effective concentration to inhibit mycelium growth by $50 \%\left(\mathrm{EC}_{50}\right)$ using the $d r c$ package in the $\mathrm{R}$ statistical software $(28,29)$. Analyses of variance (ANOVA) to test for significance among populations from California, Oregon, and Washington were conducted in $\mathrm{R}$ (28), and box plots were graphed using the ggplot 2 package (35).

Genetic variation of Phytophthora isolates. Amplified fragment length polymorphism (AFLP) analysis was conducted to determine: (i) genotypic diversity among $P$. rubi isolates, (ii) if $P$. $r u b i$ isolates cluster by state, and (iii) how diverged $P$. rubi is from its closest relative $P$. fragariae and other clade 7 relatives (2). Species selected for comparison, in addition to the 10 isolates of $P$. rubi, included $P$. fragariae, $P$. cambivora, $P$. alni, and $P$. uliginosa. AFLP was performed using the AFLP Microbial Fingerprinting kit (Applied Biosystems) with slight modifications from the manufacturer's instructions as described previously (9). Total genomic DNA was extracted from mycelia using the FastDNA SPIN kit (MP Biomedicals LLC, Solon, OH).

Restriction fragments were generated from genomic DNA (175 to $225 \mathrm{ng}$ ) with EcoRI and MseI endonucleases, while doublestranded adaptor oligonucleotides were ligated to the ends of the restricted DNA. Next, a preselective amplification of ligated fragments, diluted 1:5 in ultrapure water, using EcoRI +0 and $M s e \mathrm{I}+$ 0 primers was performed. The preselective amplification, also diluted 1:5 in ultrapure water, was followed by a selective amplification using fluorescently labeled EcoRI primers in two primer combinations (EcoRI-AC/MseI-AC and EcoRI-AA/MseI-CC). All amplifications used a Veriti 96 Well Thermal Cycler (Applied Bio- 
systems). Selective amplification products $(1.5 \mu \mathrm{l})$, combined with deionized formamide $(8.25 \mu \mathrm{l})$ and internal size standard GeneScan-500LIZ ( $0.25 \mu \mathrm{l}$, Applied Biosystems), were denatured and loaded for electrophoresis on a 3100 Avant Genetic Analyzer (Applied Biosystems). Electropherograms were analyzed using GeneMapper version 3.7 software (Applied Biosystems). All AFLP analyses were replicated 2 or more times. The peaks on electropherograms were scored as present (1) or absent (0) based on the consistency between duplicate runs.

Genetic distance among AFLP genotypes was calculated using Nei's unbiased genetic distance (26) as implemented in Tools for Population Genetic Analyses (TFPGA) version 1.3 (23). The genetic distance matrix was imported into MEGA version 4 (32) to construct a UPGMA dendrogram. Support for isolate groupings was assessed using 1,000 bootstrap replications.

\section{Results}

Phytophthora isolation from raspberry root, cane, and soil samples. A total of 275 red raspberry samples symptomatic for Phytophthora infections were collected from red raspberry fields in Oregon, Washington, and California (Table 1). Comparison of the three isolation methods highlighted that significantly more isolates were collected using the cane method compared to the bait and root isolation methods $(P=0.001$; Table 2$)$. Overall, the cane isolation method yielded more isolates of $P$. rubi, a higher percentage of isolates per plant, and a greater number of plants from which $P$. rubi was collected. The mean number of isolates collected per plant using the cane method was 1.12, whereas the numbers of isolates collected from plants using the root and bait methods were not significantly different $(P=0.748)$ at 0.45 and 0.43 isolates per plant, respectively.

Identification of Phytophthora spp. in western state raspberries. All isolates, except one, were identified as $P$. rubi based on ITS species identification (Table 1). An isolate from field WA2 in southwestern Washington was identified as P. bisheria, a recently named species first identified on wild raspberry species in Australia, the Netherlands, and the eastern United States (1).

Pathogenicity of $P$. rubi isolates. Isolates of $P$. rubi caused significantly more damage to raspberry than both of the controls (flooded and nonflooded) for all measured parameters in both studies. The mean foliage rating for the two controls in both studies were lower than the inoculated plants and ranged from 0.48 to 0.63 (Fig. 2A and B). The mean foliage rating of plants exposed to $P$. rubi isolates from both studies ranged from 1.89 to 2.67. Plants grown in the presence of $P$. rubi isolates scored higher root rating scores, measured less foliage biomass, and had shorter root lengths compared to controls (Figs. 2 and 3). To determine if isolates from a single state were more virulent, comparisons were made by grouping isolates into state of origin. Results from the two studies were not consistent; therefore, comparisons between and among states were difficult to assess. In study 1, overall, isolates from California were significantly more virulent than isolates from Oregon and Washington. Plants exposed to the California isolates were ranked (Wilcoxon rank sums, $P=0.001$ ) with the highest foliage and root rating scores with means of 2.39 and 8.31 , respectively, and shortest root length with a mean of $14.20 \mathrm{~cm}$ (Tukey-Kramer HSD, $\alpha=0.05$ ). Measurements of foliage biomass were less conclusive. Both Oregon and California isolates resulted in significantly lower foliage biomass (Tukey-Kramer HSD, $\alpha=0.05$ ) than Washington at $1.27 \mathrm{~g}$ and $1.37 \mathrm{~g}$, respectively, versus $1.53 \mathrm{~g}$ for Washington (Fig. 2A and B).

Conflicting results were observed in study 2. Overall, isolates from Oregon and Washington were more virulent than isolates from California. Plants grown in soil inoculated with isolates from Oregon and Washington had similar foliage (2.69 and 2.62, respectively) and root (8.69 and 8.51, respectively) mean ratings, while those grown in soil inoculated with California isolates had a foliage mean rating of 2.50 and root mean rating of 7.96 , which were ranked significantly higher (Wilcoxon rank sums, $P=0.001$ ). Similar results were observed for dry foliage biomass; plants grown in the presence of Oregon and Washington isolates had significantly lower mean weights of $1.17 \mathrm{~g}$ and $1.27 \mathrm{~g}$, respectively, than those grown in the presence of California isolates with a mean weight of $1.40 \mathrm{~g}$ (Tukey-Kramer HSD, $\alpha=0.05$ ). Washington isolates resulted in significantly shorter root lengths with a mean of $15.6 \mathrm{~cm}$ compared to Oregon and California isolates at $16.5 \mathrm{~cm}$ and $17.6 \mathrm{~cm}$, respectively.

Pairwise comparisons of the isolates were made to determine if some isolates were more virulent than others. Few consistent conclusions could be made due to the variation observed in each measured plant characteristic within and between studies.

Sensitivity of $\boldsymbol{P}$. rubi isolates to mefenoxam. The $\mathrm{EC}_{50}$ frequency distributions showed no significant differences among populations from Washington, Oregon, and California in an analysis of variance $(P=0.57)$. Median $\mathrm{EC}_{50}$ values were $0.062 \mu \mathrm{g} / \mathrm{ml}$, $0.064 \mu \mathrm{g} / \mathrm{ml}$, and $0.056 \mu \mathrm{g} / \mathrm{ml}$ for $P$. rubi isolates from Washington, California, and Oregon, respectively (Fig. 4).

Table 2. Collection and detection of Phytophthora rubi isolated from raspberry (Rubus ideaus) using three isolation methods and polymerase chain reaction $(\mathrm{PCR})$ detection

\begin{tabular}{lccc}
\hline & \multicolumn{3}{c}{ \% of plants with P. rubi collected } \\
\cline { 2 - 4 } Site & Root isolation & Cane isolation & Bait isolation \\
\hline WA1 & 18.9 & 48.6 & 0 \\
WA2 & 25.6 & 17.9 & 10.8 \\
WA3 & 0 & 2.5 & 0 \\
OR1 & 13.6 & 27.2 & 4.5 \\
OR2 & 15.8 & 15.6 & 9.3 \\
OR3 & 13.1 & 15.7 & 7.9 \\
CA1 & 21.0 & 73.7 & 31.6 \\
CA2 & 19.2 & 76.9 & 19.2 \\
Average & 18.9 & $37.8^{\mathrm{a}}$ & 10.5 \\
\hline
\end{tabular}

a Significantly more isolates were collected using the cane method according to Fisher exact test on binomial data $(P<0.001)$.

Table 1. Number of Phytophthora isolates and identification of Phytophthora species collected from red raspberry (Rubus idaeus) fields in Washington, Oregon, and California

\begin{tabular}{|c|c|c|c|c|c|}
\hline Site & Location & $\begin{array}{l}\text { Samples } \\
\text { collected }\end{array}$ & $\begin{array}{l}\text { Isolates recovered } \\
(3 \text { methods })^{a}\end{array}$ & $\begin{array}{l}\text { Isolates sequenced } \\
\text { from total collected }\end{array}$ & \% P. rubi \\
\hline WA1 & Burlington, WA & 37 & 132 & $48(41 \%)$ & 100 \\
\hline WA2 & Vancouver, WA & 39 & 95 & $33(35 \%)$ & $97^{c}$ \\
\hline WA3 & Woodland, WA & 40 & 4 & $2(50 \%)$ & 100 \\
\hline OR1 & Jefferson, OR & 44 & 69 & $29(60 \%)$ & 100 \\
\hline OR2 & Jefferson, OR & 32 & 11 & $6(54 \%)$ & 100 \\
\hline OR3 & Corvallis, OR & 38 & 55 & $15(26 \%)$ & 100 \\
\hline CA1 & Watsonville, CA & 19 & 82 & $52(63 \%)$ & 100 \\
\hline $\mathrm{CA} 2$ & Watsonville, CA & 26 & 149 & $25(17 \%)$ & 100 \\
\hline
\end{tabular}

a Total number of isolates collected from the cane, root, and baiting isolation methods.

b Number and percentage of isolates collected from each field that were sequenced at the internal transcribed spacer (ITS) region for identification of Phytophthora species (10).

c One isolate of P. bisheria was collected from WA2. 
Genotypic diversity of $\boldsymbol{P}$. rubi isolates. AFLP analysis was conducted on a sample of $10 P$. rubi isolates collected from various fields from Oregon, Washington, and California. Six genotypes were observed among the 10 isolates, and isolates from different fields and states appeared to share genotypes (Fig. 5). Several genotypes were observed from Oregon and Washington fields. Interestingly, the lone isolate from California has a unique genotype that nested within fingerprints of the Oregon and Washington isolates (Fig. 4). The P. rubi clade is well-supported and is clearly distinct from the closely related species $P$. fragariae (bootstrap value of 0.96 ).

\section{Discussion}

Using a systematic approach encompassing three different isolation methods, we were able to collect populations of Phytophthora spp. from red raspberry, identify them, and use these isolates for further comparisons. We found that the main causal agent of Phytophthora root rot in red raspberry in the western United States is $P$. rubi. Our results show that isolates collected from Oregon, Washington, and California do not have geographic structure, hence may belong to one large western North America population.

Isolation of Phytophthora from root samples is notoriously labor intensive and difficult because of slow growth and co-inhabitation with other fungal and oomycete species. Historically, isolating for $P$. rubi has integrated isolating from small, washed red raspberry roots and/or baiting soil with young red raspberry plants $(17,31)$. To our knowledge, isolation directly from red stele lesions has not been utilized nor published for the isolation of $P$. rubi. When directly comparing all three isolation methods, direct cane isolation proved the most successful and least labor intensive method; more Phytophthora isolates were isolated using the direct cane method compared to root isolation or soil baiting. Cane isolation has also
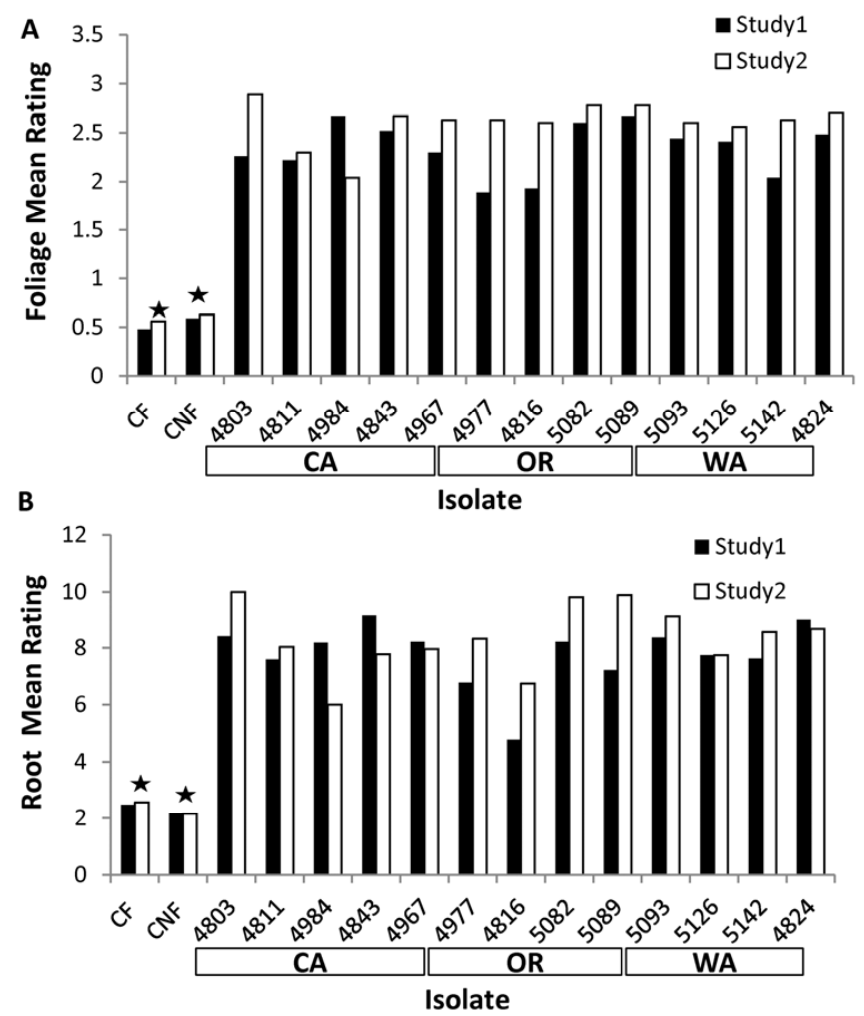

Fig. 2. A, Mean foliage rating and $\mathbf{B}$, mean root rating were measured on red rapsberry inoculated with Phytophthora rubi after 4 weeks. Foliage was rated on a 0 to 4 scale where 0 represented healthy foliage and 4 represented dead foliage. Each root system was rated on the 0 to 12 Horsfall-Barratt scale (14), with 0 being $0 \%$ diseased roots and 12 being 100\% diseased roots. In both studies (white and black bars), all isolates of $P$. rubi caused stunting of foliage (A) and roots $(B)$ on red raspberry seedlings compared with control samples (indicated by *). No differences were observed between isolates from different states. been used for the isolation of several Phytophthora species that cause root rot in woody plant/tree species, such as $P$. lateralis on Chamaecyparis lawsoniana (8), P. gonapodyides and P. lacustris isolated from Alder (Alnus glutinosa) (25), and P. cactorum and $P$. citrophthora on fruit trees in Bulgaria (24). Isolating directly from the cane is a simple and clean method that would be useful for other soilborne Phytophthora species where root lesions lead up to the crown root or cane/stem.

Ten Phytophthora species have been reported associated with root rot of raspberry in North America, South America, and Europe including $P$. rubi, P. erythroseptica, P. megasperma, $P$. citricola, and $P$. citrophthora $(5,36-38)$. The Whatcom County survey in Washington (19) indicated that possibly multiple Phytophthora species were associated with Phytophthora root rot in the region and raised the question whether root rot of raspberry is caused by one species, probably $P$. rubi, or whether the disease was caused by a Phytophthora species complex. To answer this question, a large portion of the isolates collected during this research were identified to species using the ITS region (10). With the exception of one isolate collected in Washington, all of the Phytophthora isolates collected from the western states were $P$. rubi. Results from the Whatcom County PCR survey may have been due to the presence of soil Phytophthora or secondary pathogens. Our results are in concurrence with another study (39), were Phytophthora isolates collected from raspberry were compared based on colony and growth characteristics, the production and morphology of gametangia, dimensions of sporangia, and pathogenicity. This morphologi-
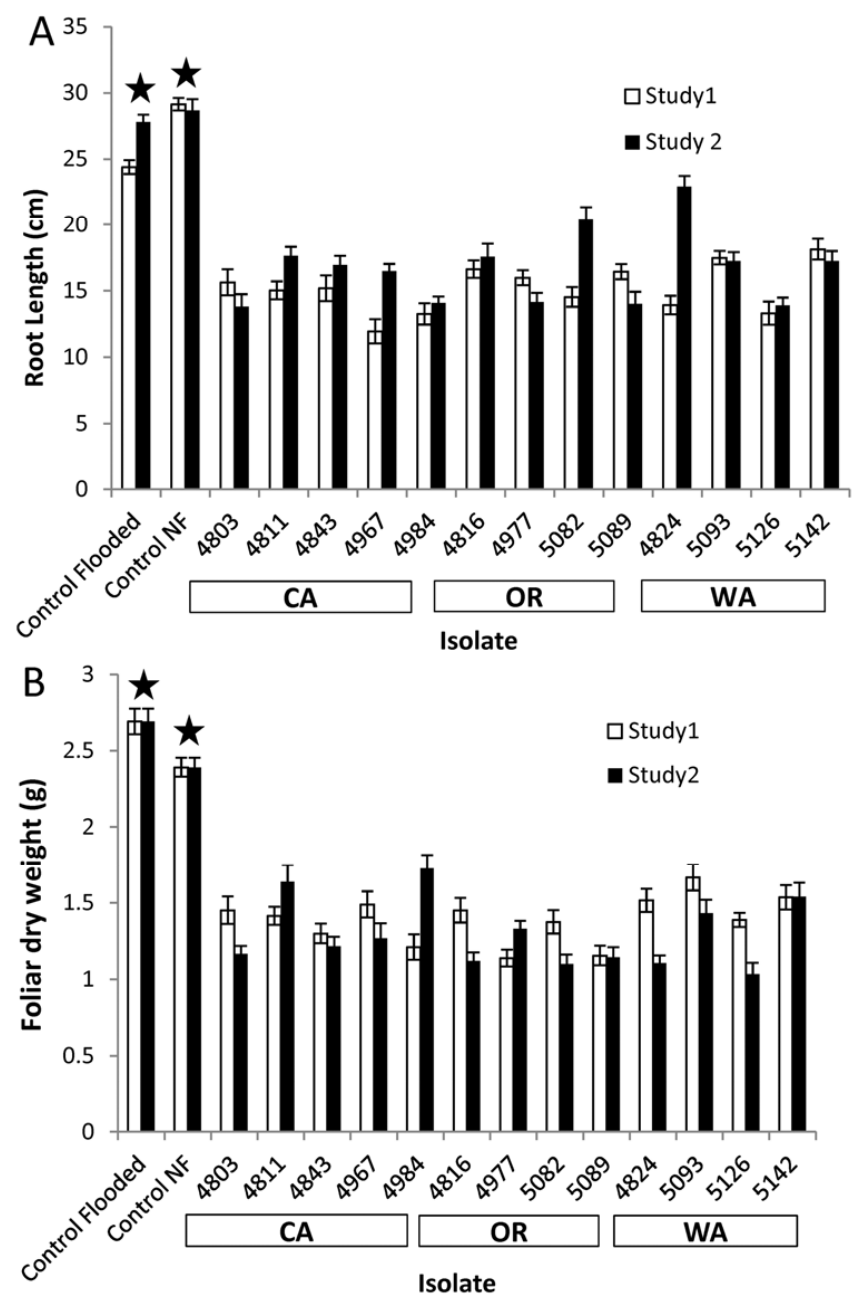

Fig. 3. A, Mean root growth and B, mean foliage dry weight were measured on red raspberry inoculated with Phytophthora rubi after 4 weeks. In both studies (white and black bars), all isolates of $P$. rubi stunted red raspberry seedlings root $(A)$ and foliar (B) growth compared with control samples (indicated by *). No differences were observed between isolates from different states. 
cal analysis placed Phytophthora isolates into one homogeneous group, distinct from all other species including $P$. fragariae collected from strawberry (21). We did, however, collect one isolate identified as $P$. bisheria, described in 2008, a slow-growing species associated with root rot of strawberries in North Carolina, roses in the Netherlands, and wild raspberry in Australia (1). Based on ITS sequence, $P$. bisheria is most closely related to $P$. citricola and other species within the ITS clade 2 (2). Pathogenicity of $P$. bisheria to strawberry was confirmed by Abad et al. (1); however, pathogenicity to red raspberry and comparisons to $P$. rubi should be included in further work.

Our pathogenicity assays, as well as our genetic analyses showed similar results indicating that isolates from Oregon, Washington, and California are phenotypically and genetically similar. The pathogenicity trials conducted here were statistically variable. No single isolate(s) appeared more virulent in both trials when examining all measures of virulence, including root and foliage ratings, root length, and mean foliage biomass. From our genetic analyses, isolates collected from red raspberry fields from Oregon, Washington, and California appear to be one panmictic population, not isolated populations separated by geographic location. $P$. rubi is thought be an endemic pathogen in the Pacific Northwest (6) and our results support this. There does not appear to be any correlation between variation in virulence and/or genetic variation associated with geographic location. Growing practices and cultivar preferences vary considerably among Oregon, Washington, and California fields. The movement of isolates during nursery shipments is the most plausible way for dispersal of individual isolates. However, in Oregon and Washington, growers typically grow on a 5 to 8 year rotation with floricane-fruiting raspberry plants, while in California, primocane fruiting red raspberry is grown on a shorter

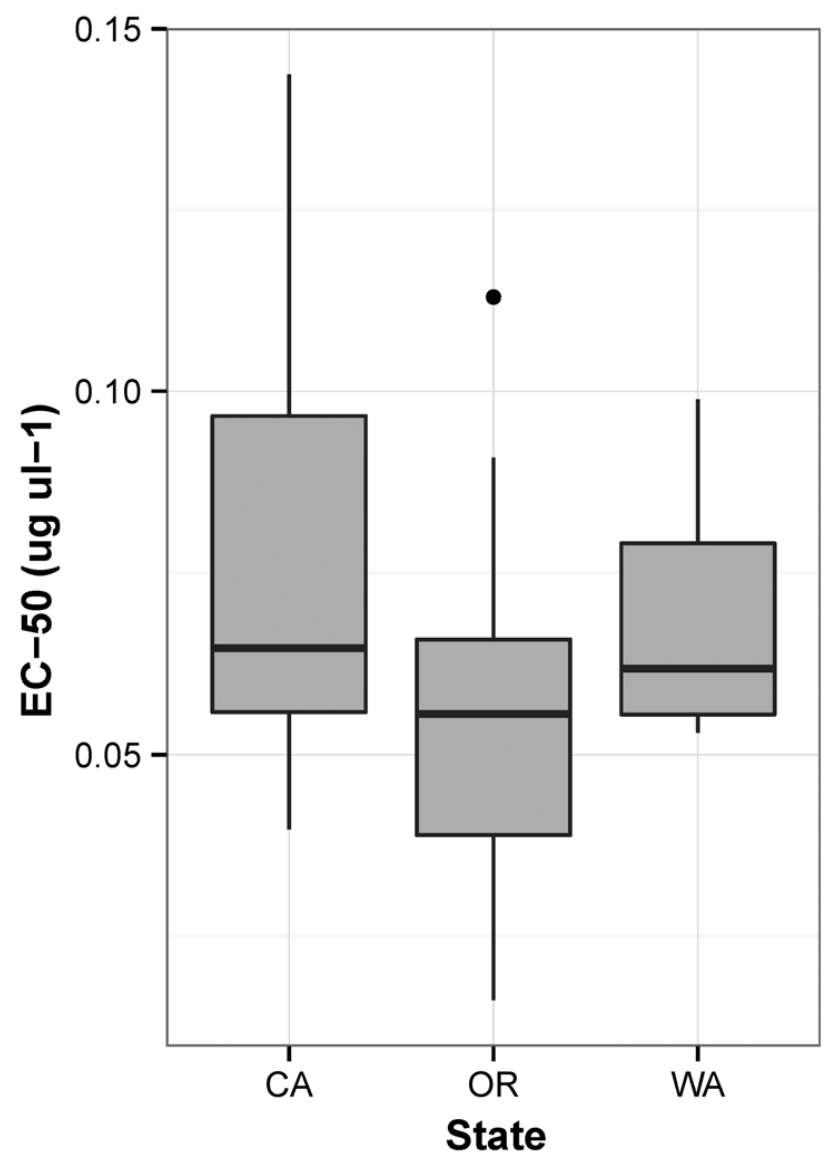

Fig. 4. Boxplots showing distributions of $\mathrm{EC}_{50}$ values for sensitivity to mefenoxam in populations from California (CA), Oregon (OR), and Washington (WA). The bold line shows the median, the upper and lower box show the 25th and 75th percentile, and whiskers show the 5th and 95th percentile, respectively. One outlier is shown as a dot.
18 -month cycle $(3,16,27)$. The movement of plant material and soil thereby would be limited, suggesting geographic isolation. Our genetic analyses in the study were limited; a more comprehensive genetic study including all the isolates collected will provide further insight into the population structure of $P$. rubi isolates from Oregon, Washington, and California.

We did not observe significant differences in the mefenoxam resistance between $P$. rubi isolates from different states. Considering the ability of other Phytophthora species to rapidly develop fungicide resistance and the fungicide usage within each state, we had expected to see resistance developing. Washington and California are the top U.S. producers of raspberry, with Washington producing $90 \%$ of the processed-raspberry production and California producing $90 \%$ of the fresh-market raspberry (33). Oregon produces about $10 \%$ of the processed-raspberry and $5 \%$ of the freshmarket raspberries within the United States (30). With frequent applications of mefenoxam, which is commonly used as a fungicide in Washington and California, mefenoxam resistance would be expected to develop quickly.

Previous work on $P$. infestans showed that in a single growing season in Mexico, there was directional selection for mefenoxam resistance in field populations (11). Research on the genetic basis for resistance to metalaxyl shows one dominate gene, with minor genes also playing a role (18). Despite population genetic similarities and virulence similarities among $P$. rubi in Washington, Oregon, and California, isolates that are under different selective pressures within a field could quickly develop resistance. Thus, growers should be cautious and use best practices to avoid development of resistance to mefenoxam.

Results from our study show that root rot on raspberry grown in the western United States is predominately caused by $P$. rubi and not as previously reported caused by a complex of Phytophthora species. Our results suggest that $P$. rubi in the western United States may represent one population with little apparent substructuring. From a plant breeding perspective, this will enhance resistance breeding strategies; plant breeders can have confidence that identified resistance to a specific $P$. rubi isolate will have broad application across regions that produce raspberry. Our results indicate that fungicide resistance may not currently be an issue within the western U.S. raspberry industry. Every effort should be made to deploy a fungicide program in raspberry to avoid emergence of resistance.

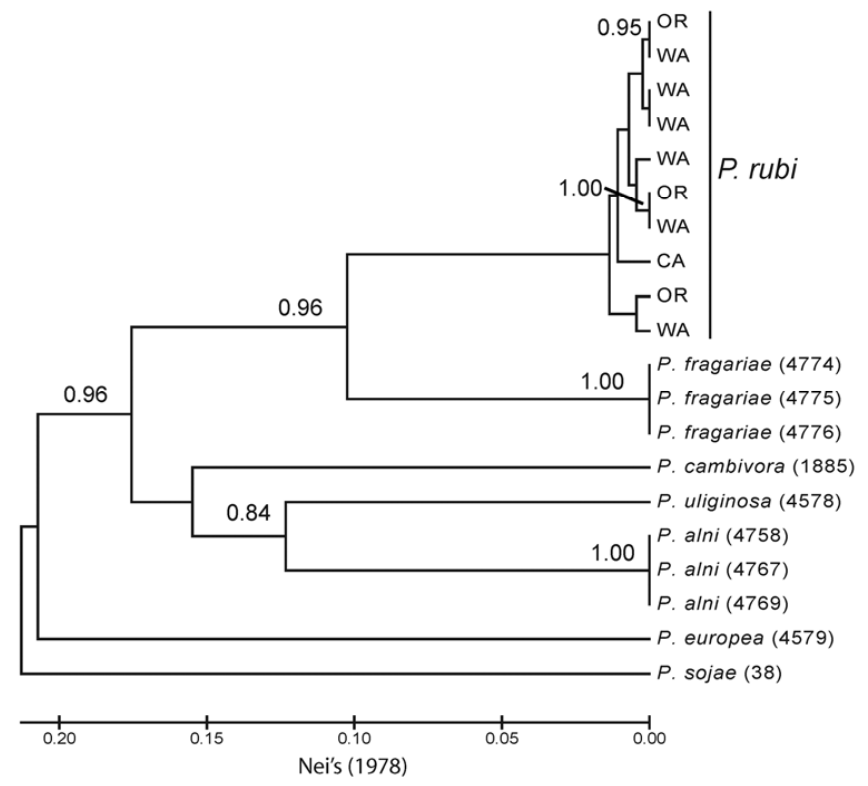

Fig. 5. A dendrogram of genetic distance generated using amplified fragment length polymorphism (AFLP) for Phytophthora rubi isolates collected from Oregon, Washington, and California compared with other closely related Phytophthora species. Percent node support was calculated for 1,000 bootstrap samples. 


\section{Acknowledgments}

We thank Jenny Broome and the Driscolls Team and Mark Bolda, University of California Extension, for help in sample collections and isolation method ideas. We thank Tom Walters and Peerbolt Crop Management for help with collections, and Karan Fairchild and Kim Henslee for excellent laboratory assistance. This work was supported by funds from USDA ARS CRIS Project 535822000-039-00D and USDA-NIFA-RAMP Project 2010-511001-21649. Mention of trade names or commercial products in this manuscript is solely for the purpose of providing specific information and does not imply recommendation or endorsement.

\section{Literature Cited}

1. Abad, Z. G., Abad, J. A., Coffey, M. D., Oudemans, P. V., Man in't Veld, W. A., deGruyter, H., Cunnington, J., and Louws, F. J. 2008. Phytophthora bisheria sp. nov., a new species identified in isolates from Rosaceous raspberry, rose and strawberry in three continents. Mycologia 100:99-110.

2. Blair, J. E., Coffey, M. D., Park, S. Y., Geiser, D. M., and Kang, S. 2008. A multi-locus phylogeny for Phytophthora utilizing markers derived from complete genome sequences. Fungal Genet. Biol. 45:266-277.

3. Bolda, M., Gaskell, M., Mitcham, E., and Cahn, M. 2012. Fresh Market Caneberry Production Manual. University of California Agriculture and Natural Resources. Publ. 3525:65.

4. Duncan, J. M., Kennedy, D. M., and Scott, P. H. 1991. Relationships between non-papillate soilborne species of Phytophthora: Root rot of raspberry. Pages 129-147 in: Phytophthora. J. A. Lucas, R. C. Shattock, D. S. Shaw, and L. R. Cooke, eds. Cambridge University Press, Cambridge, U.K.

5. Duncan, J. M., Kennedy, D. M., and Seemüller, E. 1987. Identities and pathogenicities of Phytophthora spp. causing root rot of red raspberry. Plant Pathol. 36:276-289.

6. Gigot, J. A., Walters, T. W., and Zasada, I. A. 2013. Impact and occurrence of Phytophthora rubi and Pratylenchus penetrans in commercial red raspberry (Rubus ideaus) field in Northwestern Washington. Int. J. Fruit Sci. 13:352-357.

7. Gigot, J. A., Zasada, I. A., and Walters, T. W. 2013. Integration of brassicaceous seed meals into red raspberry production systems. Appl. Soil Ecol. 64:23-31.

8. Green, S., Brasier, C. M., Schlenzig, A., McCracken, A., MacAskill, G. A., Wilson, M., and Webber, J. F. 2013. The destructive invasive pathogen Phytophthora lateralis found on Camaecyparis lawsoniana across the UK. Forest Pathol. 43:19-28.

9. Grünwald, N. J., and Hoheisel, G. A. 2006. Hierarchical analysis of diversity, selfing, and genetic differentiation in populations of the oomycete Aphanomyces euteiches. Phytopathology 96:1134-1141.

10. Grünwald, N. J., Martin, F. N., Larsen, M. M., Sullivan, C. M., Press, C. M., Coffey, M. D., Hansen, E. M., and Parke, J. L. 2011. Phytophthora-ID.org: A sequence-based Phytophthora identification tool. Plant Dis. 95:337-342.

11. Grünwald, N. J., Sturbaum, A. K., Montes, G. R., Serrano, E. G., LozoyaSaldaña, H., and Fry, W. E. 2006. Selection for fungicide resistance within a growing season in field populations of Phytophthora infestans at the center of origin. Phytopathology 96:1397-1403.

12. Heiberg, N. 1995. Control of root rot of red raspberry caused by Phytopthora fragariae var. rubi. Plant Pathol. 44:153-159.

13. Hoashi-Erhardt, W. K., Moore, P. P., Windom, G. E., and Bristow, P. R. 2008. Field and greenhouse response of red raspberry genotypes to root rot. HortScience 43:1367-1370.

14. Horsfall, J., and Barratt, R. 1945. An improved grading system for measuring plant disease. Phytopathology 35:655.

15. Jeffers, S. N., and Martin, S. B. 1986. Comparison of two media selective for Phytophthora and Pythium species. Plant Dis. 70:1038-1043.

16. Jennings, D. L., Daubeny, H. A., and Moore, J. N. 1990. Blackberries and raspberries. Acta. Hortic. 290:1380-1384.
17. Koprivica, M., Dulic-Markovic, I., Jevtic, R., and Cooke, D. E. L. 2009. Methods for detection of Phytophthora fragariae var. rubi on raspberry. Pestic. Phytomed. 24:177-184.

18. Lee, T. Y., Mizubuti, E., and Fry, W. E. 1999. Genetics of metalaxyl resistance in Phytophthora infestans. Fungal Genet. Bio1. 26:118-130.

19. MacConnell, C. 2009. Whatcom County IPM Project. Survey for Phytophthora fragariae var. rubi in pre-plant stocks and planted root samples of red raspberry in Washington State. Online publication: http://whatcom. wsu.edu/ag/IPM/phytophthora.htm

20. Maloney, K. E., Wilcox, W. F., and Sanford, J. C. 1993. Raised beds and metalaxyl for control of Phytophthora root rot of raspberry. HortScience 28:1106-1108.

21. Man in't Veld, W. A., and Willem, A. 2007. Gene flow analysis demonstrates that Phytophthora fragariae var. rubi constitutes a distinct species, Phytophthora rubi comb. Mycologia 99:222-226.

22. Menzies, G. W. 1999. Crop profile for raspberries (red) inWashington. Washington State University, Cooperative Extension, Pullman, WA.

23. Miller, M. P. 1997. Tools for Population Genetic Analyses (TFPGA) 1.3: A Windows program for the analysis of allozyme and molecular population genetic data. Distributed by the author at http://www.marksgenetic software.net/

24. Nakova, M. 2010. Monitoring of Phytophthora species on fruit trees in Bulgaria. Eur. J. Plant Pathol. 128:517-525.

25. Nechwatal, J., Bakonyi, J., Cacciola, S. O., Cooke, D. E. L., Jung, T., Nagy, Z. A., Vannini, A., Vettraiono, A. M., and Brasier, C. M. 2012. The morphology, behaviour and molecular phylogeny of Phytophthora taxon and its redesignation as Phytophthora lacustris sp. nov. Plant Pathol. 62:355-362.

26. Nei, M. 1978. Estimation of average heterozygosity and genetic distance from a small number of individuals. Genetics 89:583-590.

27. Pritts, M. 2008. Primocane-fruiting raspberry production. HortScience 43:1640-1641.

28. R Core Team. 2013. R: A language and environment for statistical computing. R Foundation for Statistical Computing, Vienna, Austria. ISBN 3900051-07-0, URL: http://www.R-project.org

29. Ritz, C., and Streibig, J. C. 2005. Bioassay analysis using R. J. Stat. Software 12:1-12.

30. Ruan, J., Buccola, S., and Pick, D. 2007. USDA's trade adjustment assistance for farmers: The raspberry industry. Agribusiness 23:101-115.

31. Schlenzig, A., Cooke, D. E. L., and Chard, J. M. 2005. Comparison of baiting method and PCR for the detection of Phytophthora fragariae var rubi in certified raspberry stocks. Bull. OEPP/EPPO 35:87-91.

32. Tamura, K., Dudley, J., Nei, M., and Kumar, S. 2007. MEGA4: Molecular Evolutionary Genetics Analysis (MEGA) software version 4.0. Mol. Bio. Evol. 24:1596-1599.

33. U.S. Dep. Agric. Natl. Agric. Stat. Ser. 2010. United States

34. Walters, T. W., and Pinkerton, J. N. 2008. Methyl bromide alternatives for raspberry nursery: First year progress. Online publication: http:// groups.ucanr.org/pacificmba

35. Wickhan, H. 2009. ggplot2: Elegant graphics for data analysis. Springer, New York.

36. Wilcox, W. F. 1989. Virulence and isolation frequency of seven Phytophthora spp. causing root rot of raspberry in New York. Phytopathology 79:93-101.

37. Wilcox, W. F., and Latorre, B. A. 2002. Identities and geographic distributions of Phytophthora spp. causing root rot of red raspberry in Chile. Plant Dis. 86:1357-1362.

38. Wilcox, W. F., Pritts, M. P., and Kelly, M. J. 1999. Integrated control of Phytophthora root rot of red raspberry. Plant Dis. 83:1149-1154.

39. Wilcox, W. F., Scott, P. H., Hamm, P. B., Kennedy, D. M., Duncan, J. M., Brasier, C. M., and Hansen, E. M. 1993. Identity of a Phytophthora species attacking raspberry in Europe and North America. Mycol. Res. 97:817-831. 